\title{
ARQUEOLOGIA SUBAQUÁTICA, ARQUEOLOGIA PÚBLICA E BRASIL
}

\section{A U T O R A}

Marina Fontolan

fontolan_marina@yahoo.com.br
Aluna de Mestrado em História Cultural pela Universidade Estadual de Campinas (UNICAMP); Linha Genêro, Identidade, Cultura Material e Cartografia, sob a orientação do Professor Doutor Pedro Paulo Abreu Funari. Pesquisa financiada pela Fundação de Amparo à Pesquisa do Estado de São Paulo (FAPESP).

\section{R E S U M O}

O objetivo deste artigo é abrir debates sobre como a Arqueologia Subaquática pode se valer do conceito e das prerrogativas da Arqueologia Pública no sentido de garantir (ou não) que o patrimônio cultural submerso seja protegido, mesmo que seja sem o respaldo legislativo. Para tal, analiso brevemente o desenvolvimento da arqueologia no país, mostrando, sobretudo, como se dá a proteção deste patrimônio no que concerne às leis envolvidas. Então, passo a apresentar algumas possibilidades de atuação dos profissionais da Arqueologia de modo que eles possam envolver o público em geral na preservação deste patrimônio. Isto, de forma a abrir caminhos para debates dentro da área no que concerne à atuação do profissional da Arqueologia frente a seu trabalho.

\section{Palavras chave: Arqueologia Subaquática, Arqueologia Pública, Arqueologia Brasileira.}

The main goal of this paper is to set debates on how Underwater Archaeology could draw from the concepts and prerogatives of Public Archaeology in a way to guarantee (or not) that the underwater cultural heritage to be protected, even without a proper legislation for it. For this, I analyze the development of Archaeology in Brazil, focusing on the laws involved on protecting or not our heritage. Then, I present some possibilities of action, where the archaeologists may involve the general public in heritage preservation. The idea is to set debates within the area regarding the performance of the archaeologists towards their work.

Keywords: Underwater Archaeology, Public Archaeology, Brazilian Archaeology.

Quando falamos em Arqueologia para pessoas que não estão direta ou indiretamente envolvidas com a área, podemos nos deparar com os mais diversos tipos de reações: perguntam-nos sobre as "verdades" do passado, sobre a necessidade de ficar decorando datas, sobre teorias da conspiração ou sobre nossas aventuras. Nestas conversas, notamos o quão rico é o imaginário de uma pessoa no que se trata da Arqueologia, mas este se distancia bastante daquilo que poderíamos chamar de ofício do profissional da Arqueologia. Raros os casos que nos perguntam sobre trabalhos em laboratórios ou sobre quanto tempo nos dedicamos à leitura. Os que perguntam sobre trabalhos de campo talvez esperem a descrição de aventuras estilo Indiana Jones, não uma descrição de escavação meticulosa, feita em horas de trabalho. 
Isto tudo pode voltar a vir à tona quando o arqueólogo diz que sua especialidade é Arqueologia Subaquática. Neste ponto, as pessoas podem começar a imaginar um aventureiro de roupa de mergulho, buscando verdades sobre os grandes segredos da humanidade, como a Atlântida. Outra possível reação é perguntar diretamente: "o quê é isto?". Ou seja, podemos notar, assim, que a pessoa pode conceber o que é Arqueologia, mas nem sempre ela pode perceber, com a mesma facilidade da área médica, que haja especialidades dentro do campo. E é exatamente neste momento que o arqueólogo deve ser criterioso em sua resposta, para não criar a noção de que o profissional atua como o Indiana Jones, mas debaixo da água!

O objetivo deste artigo será pensar como o conceito de Arqueologia Pública pode ajudar os/as arqueólogos/as subaquáticos e demais profissionais da área a reverter este quadro, não pretendendo com isso se tornar um guia definitivo, mas buscar espaços para debater o assunto. Desta forma, pensar maneiras de fazer a Arqueologia Subaquática se aproximar do imaginário do público geral se torna fundamental, além de, é claro, fazer uma discussão sobre qual a forma de arqueologia pública pode-se construir neste país para que se possa garantir a savalguarda do patrimônio submerso.

Para tal, num primeiro momento, se pensará o que é Arqueologia, Arqueologia Subaquática e Arqueologia Pública. Então, passo a levantar discussões sobre os problemas que a prática da Arqueologia Subaquática enfrenta no Brasil atualmente. Com isto, busco pensar algumas possibilidades de atuação dos profissionais da Arqueologia, de forma a envolver o público geral nas problemáticas acerca do patrimônio submerso.

A Arqueologia é entendida, aqui como uma disciplina que visa a interpretação de um passado através da cultura material, buscando entender as relações sociais e as transformações pelas quais as sociedades humanas passaram (cf. FUNARI, 2006). Assim sendo, a disciplina ganha um caráter amplo, pois ela passa a ter um aspecto que é, simultaneamente, histórico e antropológico (idem: 18). A criação de especialidades neste contexto mais geral acabou sendo uma via para que os pesquisadores pudessem reunir e interpretar seus dados.

Pode-se, desta forma, colocar tanto a Arqueologia Subaquática quanto a Arqueologia Pública neste contexto mais amplo de criação de especialidades na Arqueologia. No primeiro caso, temos a especificidade de interpretar aquilo que foi encontrado debaixo da água. É interessante notar que a Arqueologia Subaquática é a única especialidade da disciplina na qual o ambiente em que se encontram os materiais a serem escavados e estudados dão o nome da disciplina (BASS, 1971: 17). Isto se torna importante, sobretudo, no quesito de debates sobre a legislação que confere a proteção do patrimônio arqueológico. Desta maneira, esta especialidade acaba por estudar uma grande gama de materiais que vão desde embarcações até cidades inteiras. ${ }^{1}$

A Arqueologia Pública, da mesma maneira que a Subaquática, pode ser escavações e estudo do sítio conhecido por Kyrenia, que ocorreram no final da década de 1960 (Bass, 2005: 72 - 79). Além deste, há o estudo da cidade de Port Royal, na Jamaica, cuja escavação ocorreu durante toda a década de 1980 (Bass, 2005:164 - 171).

considerada como uma das várias especialidades da Arqueologia. A ideia de Arqueologia Pública não é algo estático, muito menos simples de ser definido e uma das razões disso é a noção de que a palavra público nos remete, pois pode vincular-se ao estado e à população de uma forma geral (MERRIMAN, 2004: 2). A vinculação do termo à Arqueologia passou a ser mais sistemática no início da década de 1970, estando ligado às necessidades de manejo de 
2 Texto completo da Lei $n^{\circ} 3.924 / 61$ Disponível em: http://www010. dataprev.gov.br/sislex/paginas/42/1961/3924.htm Acesso em: 12/4/2012.
3 Texto completo da Lei $n^{\circ} 10.166 / 00$ Disponível em: http://www.leidireto.com.br/lei-10166.html Acesso em 12/4/2012.

4 Art.20, § 2o, Lei no 10.166/00. Disponível em: http://www.leidireto. com.br/lei-10166.html Acesso em: 12/4/2012. recursos culturais (MERRIMAN, 2004: 4). No entanto, foi apenas atualmente que ela se tornou a responsável por voltar a Arqueologia para o interesse do público, de forma a estabelecer relações entre este, os estudiosos e suas respectivas pesquisas, garantindo a construção e o fortalecimento de identidades nacionais (CARVALHO e FUNARI, 2009). No entanto, os arqueólogos Pedro Paulo Abreu Funari e Márcia Bezerra acreditam que todo o trabalho arqueológico deve estar ligado ao público (2012: 110).

\section{As Arqueologias Brasileiras}

No país, a Arqueologia terrestre, como na maior parte do mundo (FUNARI, 2006: 23), desenvolveu-se no século XIX, passando por períodos nos quais houve ou não estímulo à ela (Funari e BeZerRA, 2012: 103-105). Ao longo desta história, diversas legislações acerca da proteção do patrimônio foram discutidas e, em 1961, a principal lei que dispõe sobre a preservação de monumentos arqueológicos e pré-históricos foi aprovada, sob o n³.924/61 (FUnARI, 2006: 26). Tal legislação é responsável por definir o que se considera um monumento arqueológico ou pré-histórico, seus usos e, também, sua propriedade. Será, justamente, na proibição do uso comercial de sítios arqueológicos e na propriedade pública dos mesmos que o patrimônio arqueológico terrestre garante sua savalguarda e sua proteção.

A Arqueologia Subaquática, no entanto, teve um desenvolvimento diferente no país, sobretudo no que se refere à proteção do patrimônio submerso. Assim, por se tratar de um estudo de caso específico sobre este tema, a análise do desenvolvimento do ramo e da legislação produzida será mais detalhada, notando como o país acabou criando, pelo menos, duas arqueologias diferentes.

A prática da Arqueologia voltada para os meios submersos está vinculada ao início oficial do mestrado de Gilson Rambelli em 1993 no Museu de Arqueologia e Etnologia da Universidade de São Paulo (MAE/USP), após especializações na área realizadas na França. Neste mesmo ano, durante a VII Reunião da Sociedade de Arqueologia Brasileira (SAB), houve a organização de uma mesa-redonda dedicada a tema (RAMBELLI, CAMARGO e CALLIPO, 2003). Até o final da década de 1990, outros dois mestrados na área foram iniciados (RAMBELLI, CAMARGO e CALLIPO, 2003). Este processo acabou tendo certa continuidade, já que outras pessoas se interessaram pela área e passaram a estudá-la. Isso ajudou a consolidar a prática da Arqueologia Subaquática no Brasil (RAMBELLI, 2004a).

No entanto, no final do ano de 2000, o governo federal promulgou a Lei Federal $n^{\circ} 10.166 / 00 .^{3}$ Esta dispõe de forma específica sobre os sítios submersos e permite "(...) estipular o pagamento de recompensa ao concessionário pela remoção dos bens de valor artístico, de interesse histórico ou arqueológico, a qual poderá se constituir na adjudicação de até quarenta por cento do valor total atribuído às coisas e bens como tais classificados". ${ }^{4}$ Ou seja, a legislação, de alguma forma, legaliza a prática comercial de exploração de sítios submersos, uma vez que garante pagamento de recompensa àquele que tiver permissão para explorar o sítio.

Neste contexto, os arqueólogos Gilson Rambelli, Paulo Fernando Bava de Camargo e Flávio Rizzi Calippo criam o Centro de Estudos de Arqueologia 
5 Os textos traduzidos são: "O Homem que roubava as estrelas" (original de 1979, traduzido por Gilsn Rambelli em 2004) e "Arqueólogos, mergulhadores desportivos e caçadores de tesouros" (original de 1985, traduzido por Gilson Rambelli em 2004b). Estes foram originalmente escritos para apoiar o projeto-lei conhecido por Abandoned Shipwreck Act. Este previa que o Estado Americano seria o responsável por reivindicar e gerenciar naufrágios abandonados que estivessem em terras submergidas que a ele pertenceriam, ou seja, os sítios seriam protegidos de explorações comerciais se estivessem num raio de três milhas náuticas a partir da costa (AUBRY, 1997:16-17). Sua aprovação deu-se em 1988 (AUBRY, 1997: 16).

6 Descrito como um mergulhador ligado ao salvamento comercial.
Náutica e Subaquática (CEANS), ainda no ano de 2000. Este acaba ganhando um espaço acadêmico no Núcleo de Estudos Estratégicos da Universidade Estadual de Campinas (NEE/UNICAMP) em 2004, tornando-se o primeiro centro de pesquisa em Arqueologia Subaquática do Brasil (NASCIMENTO, 2004). Ainda neste ano, os especialistas publicam o Livro Amarelo, uma obra cujo objetivo é divulgar a prática da Arqueologia Subaquática no Brasil. Além desta, há a tradução e a publicação de dois textos escritos por George Fletcher Bass, cujo uso deu-se, justamente, para construir uma ideia do que é a Arqueologia Subaquática e qual sua diferença da exploração comercial, conhecida entre os arqueólogos como caça ao tesouro. ${ }^{5}$

Por um lado, uma Arqueologia que tem seus sítios e achados protegidos por uma lei, que também garante que a propriedade daquilo seja pública. Por outro, uma prática construída como uma sub-área da primeira, mas cujos sítios e seus respectivos achados são tratados de forma bem diferente, garantindo que haja propriedade privada e valor monetário àquilo que for encontrado. Assim temos, no Brasil, pelo menos duas Arqueologias, que são determinadas, apenas, pelo meio no qual se pratica uma ou a outra.

\section{Arqueologia Subaquática e Arqueologia Pública: Diálogos}

Dado este contexto, torna-se importante passar a refletir como o conceito de Arqueologia Pública pode ajudar os arqueólogos subaquáticos brasileiros a buscar o interesse do público geral no tema e trazê-los para os debates acerca da proteção deste patrimônio. A importância de se envolver o público nestes debates já é tratada por George Fletcher Bass desde o final da década de 1980, quando, no prólogo do livro Ships and Shipwrecks of the Americas: $A$ History Based on Underwater Archaeology, escrito em conjunto com o capitão W.F.Searle, ${ }^{6}$ ele dá à sociedade a responsabilidade da iniciativa de apoiar a Arqueologia Subaquática ou a caça ao tesouro e, também, de fazer escolhas entre o que será escavado cientificamente e o que será autorizado para exploração comercial (BASS; SEARLE, 1988: 258). Para tal, se analisará algumas ações já tomadas e, também, se fará propostas de outras, de modo a poder criar um ambiente amplo de discussões. Vale deixar claro que o objetivo aqui não é criar um guia fechado e pronto, mas sim fornecer propostas e pontos de debates.

Creio que o primeiro ponto que deve ser pensado são questões de publicações de obras e textos sobre Arqueologia Subaquática em vários locais e com um texto acessível para o grande público. Obras que divulgam a ciência em si, como o caso do livro Arqueologia Até Debaixo D'Água, do arqueólogo Gilson Rambelli (2002), são de grande importância no que concerne a divulgar a disciplina e a chamar a atenção do público-leitor para alguns de seus debates internos. Além disto, textos escritos por especialistas diversos divulgados em sites de conteúdo aberto, ${ }^{7}$ em revistas voltadas para um público em geralı, e a disponibilidade de um manifesto, como o Livro Amarelo (2004), para download, sem dúvida, inserem um amplo público na temática. Como se pode inferir da análise da seguinte tabela, são obras que atingem um bom público e podem ser vistas como uma importante maneira de divulgar a Arqueologia Subaquática no país:
Aqui, podemos exemplificar com os textos: "Arqueologia SubaquáPaulo Bava de Camargo e Flávio Rizzi Calipo, e publicado no site http://www.ciadaescola.com.br/ zoom $/$ materia.asp? materia $=171$ em 2003. Além disto, o site História e-História (http://www.historiaehistoria.com.br/), contém diversos textos sobre o tema escritos por Gilson Rambelli, Filipe Castro e as traduções de George Fletcher Bass. As referências completas estão na bibliografia.

8 Aqui, pode-se citar o artigo escrito por Glória Tega para a Revista Mergulho n96, ano VIII (2004). 
9 No original: "(...) people are sought to be manipulated in order to make their opinions more compatible with the interests of professional archaeology".
Os desafios da Arqueologia Subaquática no Brasil, por Gilson Rambelli

O futuro do passado ameaçado, por Gilson Rambelli

Livro Amarelo

História
e-História
História
e-História
História
e-História

$02 / 2012$ a

$02 / 2012$ a

$07 / 2012$

$01 / 2012$ e $08 / 2012$
$07 / 2012$
661

91
Infelizmente, não foram obtidos a quantidade de acessos em um período anterior ao dado e, tampouco, os dados do outro texto citado. No entanto, já é uma pequena amostragem da importância deste tipo de trabalho. Desta forma, se faz necessário ampliar sempre publicações a respeito do tema voltadas para um público geral, de modo que um grande número de pessoas possam continuar tendo acesso aos debates e, também, para que elas consigam compreender a dimensão desta prática, que não se restringe apenas a navios.

No entanto, se apenas nos atermos às publicações, acabaremos por criar aquilo que o arqueólogo Cornelius Holtorf chama de Arqueologia de Relação Pública. Nesta, "(...) as pessoas são solicitadas à serem manipuladas de modo que a opinião delas sejam mais compatível aos interesses da Arqueologia profissional" (HOLTORF, 2005). ${ }^{9}$ Por isso, de uma forma mais sistematizada, podemos dizer que o Modelo de Relações Públicas visa

[...] garantir o aval social que permite a continuidade dos próprios trabalhos arqueológicos. [...] Assim, por uma questão de sobrevivência, torna-se imperativo demonstrar para a sociedade o quanto os trabalhos arqueológicos, e as memórias deles derivadas, são relevantes e, por isso, podem ser financiados com fundos públicos ou apoiados das mais diversas maneiras (CARVALHO; FUNARI, 2009).

Desta maneira, os debates sobre a proteção do patrimônio submerso acabam se restringindo apenas aos círculos acadêmicos. De que forma, então, podemos envolver o público nestes debates?

Primeiramente, creio que há a necessidade de se criar exposições interativas. Aqui pode-se pensar não apenas em museus históricos ou de arte, que são espaços onde normalmente se constrói exposições baseadas em achados arqueológicos, mas também pode-se preparar materiais e exibições para museus de ciências, que mostrem algumas especificidades de se fazer Arqueologia debaixo da água, complementando e enriquecendo as mostras sobre Arqueologia geral na instituição (BOWENS, 2009). As exposições, tanto as mais simples quanto as mais elaboradas, são capazes de introduzir o público aos trabalhos de pesquisa que estão sendo realizados e podem fazer com que a comunidade fortaleça o desejo pela proteção do sítio (BOWENS, 2009: 192). Este desejo ainda pode ser mais bem reforçado se as pessoas estiverem envolvidas na montagem da mesma.

Aliás, essa questão de envolver os não-arqueólogos em trabalhos tanto de campo como laboratoriais e na divulgação já é antiga. Já era uma preocupação para Bass em 1985, como podemos notar a partir de sua carta "Arqueólogos, mergulhadores desportivos e caçadores de tesouros": 
10 No original: "Many amateur divers oppose the Bill because they feel it is overly restrictive. (...) shipwreck site after shipwreck site had been stripped bare by amateur souvenir hunters and professional looters. [...] Some amateur divers feel that professional archaeologists oppose their having any role in shipwreck archaeology. I have never worked without amateur divers in my staff".
Muitos mergulhadores amadores se opõem ao projeto-lei porque eles sentem que ela é muito restritiva. [...] sítio de naufrágio após sítio de naufrágio foram roubados por caçadores de souvenires amadores e saqueadores profissionais. [...] Alguns mergulhadores amadores crêem que os arqueólogos profissionais são contra eles terem qualquer papel na Arqueologia de naufrágio. Eu nunca trabalhei sem mergulhadores amadores em minha equipe (BASS, 1985: 256 - tradução minha). ${ }^{10}$

Bass dá uma grande importância em ter não-arqueólogos em suas equipes de trabalho. Nesta carta, ele argumenta em favor do Abandoned Shipwreck Act, que é um projeto-lei que postula sobre a proteção do patrimônio submerso em águas americanas. Este estava sendo discutido no Senado americano nesta época e que foi promulgado em 1988 (AUBRY, 1997: 16-17). Isto, sem dúvida, é uma das maneiras de se criar um laço entre a sociedade, o trabalho do profissional da Arqueologia e o patrimônio submerso, de modo que a proteção deste se dê pela vontade da população em protegê-lo e não por meios legislativos. Além disto, o contato entre o arqueólogo e a população local de seus trabalhos ajuda a questionar o estereótipo do cientista como detentor de verdades sobre o mundo e, além disso, ajuda a população a quebrar aquela ideia de que a Arqueologia está ligada a uma aventura.

No entanto, é de grande importância entender que não são todas as pessoas que podem ter um acesso ao sítio arqueológico em si. Afinal, não são todos que podem mergulhar, por se tratar de uma prática esportiva ainda bem custosa, embora já muito mais popularizada do que os antigos escafandros. Assim, torna-se fundamental que os arqueólogos se reúnam com a comunidade para divulgar o trabalho que está sendo realizado, podendo envolvê-las em outros estágios do trabalho arqueológico. O objetivo, claro, não é impor um interesse na preservação do patrimônio que está sendo estudado, mas tentar encontrar um ponto de equilíbrio entre os diversos interesses envolvidos na preservação ou não daquele patrimônio. Desta maneira, podemos enxergar apreços e desapreços pelo chamado patrimônio, além daqueles do Estado (FUNARI; BEZERRA, 2012: 109). Afinal, não creio que baste ao profissional chegar e falar da importância de se preservar algo, pois, caso as pessoas não se relacionem com aquele bem de alguma maneira, dificilmente haverá uma luta para protegê-lo. A meu ver, ele deve entender as dimensões políticas de seu trabalho e, assim, tentar encontrar certo equilíbrio entre os diversos interesses envolvidos nele: seja relacionado ao governo, à população da comunidade, à empresa/academia que ele presta serviços e, no caso mais específico da Arqueologia Subaquática, à Marinha (atual responsável pela fiscalização dos sítios submersos).

Talvez o tempo que o profissional tenha para realizar todas suas tarefas em campo não seja suficiente para que haja um contato tão constante com o público. Assim, chamar a imprensa local e manter contato com ela pode ser uma alternativa para a divulgação dos trabalhos, sobretudo aqueles que se relacionam com a história local (BOWENS, 2009: 192-194). Este contato, claro, pode também ser feito quando o profissional também tem tempo de ter um contato mais constante com a população, afinal, a imprensa é um meio de divulgação importante. 


\section{Arqueologia Subaquática, Arqueologia Pública e Patrimônio}

Desde o início da década de 1990, com a publicação da Carta de Proteção e Gerenciamento do Patrimônio Arqueológico pelo Comitê Internacional para a Gestão do Patrimônio Arqueológico (ICAHM/ ICOMOS), tem-se a ideia de que só se consegue preservar algo caso haja afeição e conhecimento sobre aquilo (CARVALHO; FUNARI, 2009). Assim, a Arqueologia Pública passou a ganhar uma atenção cada vez maior por parte de especialistas e o mesmo deve ocorrer na Arqueologia Subaquática brasileira. Afinal, é através deste conceito que o interesse pela preservação do patrimônio subaquático pode ser garantido. Ele é capaz de gerar debates em outras esferas da sociedade, podendo acarretar na criação da necessidade de preservação daquilo, mesmo que a legislação autorize uma exploração comercial do mesmo.

O que pretendi aqui foi trazer algumas ideias acerca de como a Arqueologia pública pode fazer parte dos trabalhos de Arqueologia Subaquática no país, integrando estas duas esferas da ciência. Não pretendo, com isto, criar fórmulas sobre como agir em relação à Lei n ${ }^{\circ} 10.166 / 00$ ou como se deve dar a savalguarda do patrimônio submerso em águas brasileiras. Abrir o diálogo com a sociedade é uma das maneiras que penso como possíveis para garantir a proteção do patrimônio submerso, sem ter que contar apenas com um apoio legislativo para tal.

Agradecimentos Agradeço, primeiramente, ao meu orientador, Pedro Paulo Abreu Funari, pelo apoio a minha pesquisa no mestrado. À Aline Vieira de Carvalho, também por seu apoio. Quero agradecer a Glória Tega e a equipe que faz parte do site História e-História, pela ajuda e o fornecimento dos dados apresentados no texto, em relação aos acessos de obras sobre Arqueologia Subaquática. Também agradeço à Fundação de Amparo à Pesquisa do Estado de São Paulo (FAPESP) pelo apoio a esta pesquisa. Por fim, agradeço à Equipe do Laboratório de Arqueologia Pública do Núcleo de Estudos e Pesquisas Ambientais da Universidade Estadual de Campinas (LAP/NEPAM/UNICAMP) pelo convite para publicação nesta revista.

\section{Bibliografia}

\section{Livros}

AUBRY, Michele. "Abandoned Shipwreck Act". In: DELGADO, James P. (Editor). Encyclopedia of Underwater and Maritime Archaeology. Londres: British Museum Press, 1997. p. 16-17.

BASS, George Fletcher. Arqueologia Subaquática. $13^{\circ}$ volume da coleção História Mundi. Lisboa: Editorial Verbo, 1971.

"O Homem que roubava as estrelas". História e-História, Campinas, 2004, tradução por Gilson Rambelli. Disponível em http://www.historiaehistoria.com. $\mathrm{br} /$ materia.cfm?tb=newsletter\&id=4 Acesso em: 28/3/2009. Original de 1979. 
HOPE-SIMPSON, R. "Perspectives". Journal of Field Archaeology.

Boston, Vol. 12, No. 2, Summer, 1985. p. 256-260. http://www.jstor.org/stable/530296 Acesso em: 07/01/2009.

; SEARLE, W. F. "Shipwrecks and society". In: BASS, George Fletcher (Editor). Ships and Shipwrecks of the Americas: A History Based on Underwater Archaeology. London: Thames and Hudson, 1988. p. 256-259.

BOWENS, Amanda. "Presenting, Publicizing and Publishing Archaeological Work". In Bowens, Amanda (Editor). Underwater Archeology: The NAS Guide to Principles and Practice. Oxford \& Portsmouth: Blackwell Publishing \& Nautical Archaeology Society, 2009. p. 189-197.

CARVALHO, Aline Vieria de; FUNARI, Pedro Paulo Abreu. "Arqueologia Pública: as relações entre a academia e a sociedade". História e-História, Campinas, 2009. Disponível: http://www.historiaehistoria.com.br/materia.cfm?tb=arqueologia\&id=31 Acesso em: 27/2/2011.

CASTRO, Filipe. "Caçadores de tesouros: proposta de uma taxonomia". História E-História, Campinas, 2005. Disponível em: http://www.historiaehistoria.com.br/ materia.cfm?tb=artigos\&id=20 Acesso em: 7/3/2011.

FUNARI, Pedro Paulo Abreu. Arqueologia. $2^{a}$ edição. São Paulo: Editora Contexto, 2006.

BEZERRA, Márcia. "Public Archaeology in Latin America". In: CARMAN, John; MCDAVID, Carol; SKEATES, Robin. The Oxford Handbook of Public Archaeology. Oxford: Oxford University Press, 2012. p. 100-115.

HOLTORF, Cornelius. The Portrayal of Archaeology in Contemporary Popular Culture Opportunity or obstacle for professional archaeologists? 2005. Disponível em: http:// traumwerk.stanford.edu:3455/populararchaeology/9. Acesso em: 6/9/2012.

MERRIMAN, Nick. "Introduction: diversity and dissonance in public archaeology". In Public Archaeology. Londres, Routledge, 2004. Disponível em: http://books.google. com.br/books?id=7-LKEDXA8H8C\&printsec $=$ frontcover\&hl=pt-BR\&source $=\mathrm{gbs}$ ge_summary_r\&cad=0\#v=onepage \&q\&f=false Acesso em: 6/9/2012.

NASCIMENTO, Paulo César. "Em busca do tesouro (e da história)". Matéria publicada no Jornal da UNICAMP do dia 3 a 9 de maio de 2004.

O LIVRO AMARELO: MANIFESTO PRÓ-PATRIMÔNIO CULTURAL SUBAQUÁTICO BRASILEIRO. Campinas, Junho, 2004. CEANS / NEE / UNICAMP. Disponível em http:// www.arqueologiasubaquatica.org.br/ Acesso em 28/3/2009.

RAMBELLI, Gilson. Arqueologia Até Debaixo D'água. São Paulo: Maranta, 2002.

; CAMARGO, Paulo Brava de; CALIPPO, Flávio Rizzi. "Arqueologia Subaquática". 2003 Disponível em: http://www.ciadaescola.com.br/zoom/materia. asp?materia $=171$ Acesso em: 27/2/2011.

"Os desafios da Arqueologia Subaquática no Brasil". História E-História, Campinas, 2004a. Disponível em http://www.historiaehistoria.com.br/ materia.cfm?tb=artigos\&id=7 Acesso em $27 / 2 / 2011$ 
"O futuro do passado ameaçado". Tradução da carta "Arqueólogos, mergulhadores desportivos e caçadores de tesouros", de George F. Bass, de 1985. História E-História. Campinas, 2004b. Disponível em: http://www.historiaehistoria. com.br/materia.cfm?tb=reportagens\&ID=5 Acesso em: 27/2/2011.

"Entre o uso social e o abuso comercial: as percepções do patrimônio cultural subaquático no Brasil". História, Franca, vol.27, no. 2, pp.49-74, 2008. Disponível em: http://www.scielo.br/scielo.php?pid=S0101-90742008000200004\&script $=$ sci_ arttext Acesso em: 1/12/2010.

TEGA, Glória. "Patrimônio Submerso". Revista Mergulho. São Paulo, n96, ano VIII, 2004. p. 20-22.

\section{Sites}

- Texto completo da Lei no 3.924/61. Disponível em: http://www010.dataprev.gov.br/ sislex/paginas/42/1961/3924.htm Acesso em: 12/4/2012.

- Texto completo da Lei no 10.166/00. Disponível em: http://www.leidireto.com.br/ lei-10166.html Acesso em: 12/4/2012. 